\title{
Chumbo e cádmio em água de poços artesianos da cidade de Buenos Aires-PE
}

O município de Buenos Aires encontra-se localizado na região da Mata Norte de Pernambuco, na Zona Canavieira do Estado. O sistema de abastecimento público de água no referido município é muito precário, apesar de possuir uma grande rede de aquífero subterrâneo. Decorrente disso, existem diversos poços artesianos do tipo cacimbão escavados em diferentes localidades de Buenos Aires, e que servem como fontes de abastecimento público para os moradores. Pelo fato desses poços estarem localizados próximos de áreas consideradas potencialmente poluidora de metais pesados, nenhum plano de monitoração ambiental foi estabelecido pelos órgãos de Vigilância Sanitária Municipal ou Estadual. Sendo assim, e dentro desse contexto, o objetivo do presente trabalho foi determinar os níveis de concentração de chumbo e cádmio na água de poços artesianos do tipo cacimbão que servem como fonte de abastecimento público aos moradores do município de Buenos Aires. O cádmio e o chumbo foram determinados pela técnica de espectrometria de massa num equipamento ICP MS da marca Perkin Elmer ${ }^{\circledR}$ modelo NexION 300D ${ }^{\circledast}$. O limite de deteç̧ão (LD) do método foi de 0,6 $\mu \mathrm{g}$.L-1 para o chumbo, e de 0,1 $\mu \mathrm{g}$.L-1 para o cádmio. Todas as concentrações de chumbo e cádmio na água dos poços estudados foram menores do que LD, o que significa risco desprezível de toxicidade química, no caso de ingestão por seres humanos. Apesar de atualmente, os níveis de concentração de chumbo e cádmio na água dos poços estudados apresentarem valores desprezíveis do ponto de vista da toxicidade química, existe a necessidade de se estabelecer planejamento periódico de monitoração ambiental com a finalidade de constatar possíveis alterações da presença desses metais pesados no aquífero da região.

Palavras-chave: Monitoração Ambiental; Metais Pesados; Risco Ambiental; Saúde Pública; Saúde Humana.

\section{Lead and codium in water from artesian wells in the city of Buenos}

\section{Aires-PE}

The municipality of Buenos Aires is located in the Mata Norte region of Pernambuco, in the sugarcane zone of the State. The public water supply system in that municipality is very precarious, despite having a large underground aquifer network. As a result, there are several cacimbão artesian wells dug in different locations in Buenos Aires, which serve as sources of public supply for residents. Because these wells are located close to areas considered to potentially pollute heavy metals, no environmental monitoring plan has been established by the Municipal or State Sanitary Surveillance agencies. Therefore, and within this context, the objective of the present study was to determine the levels of lead and cadmium concentration in the water of artesian wells of the cacimbão type that serve as a source of public supply to the residents of the municipality of Buenos Aires. Cadmium and lead were determined using the mass spectrometry technique on an ICP MS equipment from Perkin Elmer ${ }^{\circledast}$ model NexION 300D ${ }^{\circledR}$. The detection limit (LD) of the method was $0.6 \mu \mathrm{g} . \mathrm{L}-1$ for lead, and $0.1 \mu \mathrm{g}$. L- 1 for cadmium. All concentrations of lead and cadmium in the water of the studied wells were lower than LD, which means a negligible risk of chemical toxicity, in case of ingestion by humans. Although currently, the levels of lead and cadmium concentration in the water of the studied wells show negligible values from the point of view of chemical toxicity, there is a need to establish periodic planning of environmental monitoring in order to verify possible changes in the presence of these metals heavy in the region's aquifer.

Keywords: Environmental Monitoring; Heavy Metals; Environmental Risk; Public Health; Human Health.

Topic: Desenvolvimento, Sustentabilidade e Meio Ambiente

Reviewed anonymously in the process of blind peer.

Cleomacio Miguel da Silva (iD)

Universidade de Pernambuco, Brasil

http://lattes.cnpq.br/4646424965040385

http://orcid.org/0000-0002-0217-1087

cleomacio@hotmail.com

Vitoria Régia de Moura Silva (iD

Universidade de Pernambuco, Brasil

http://lattes.cnpq.br/9871118336097793

http://orcid.org/0000-0003-4729-8337

vitoria.regiamoura@upe.br

Carlos Eduardo de Oliveira Costa Júnior (iD

Centro Universitário Tiradentes de Pernambuco, Brasil

http://lattes.cnpq.br/2692132363610110

http://orcid.org/0000-0003-2990-0849

oliveiracosta@msn.com

6

DOI: 10.6008/CBPC2179-6858.2021.007.0027
Received: 02/07/2021

Approved: 28/07/2021

\author{
Crescêncio Andrade Silva Filho (iD \\ Universidade Federal de Pernambuco, Brasi \\ http://lattes.cnpq.br/0987251699522230 \\ http://orcid.org/0000-0002-7410-8554 \\ candrade@cnen.gov.br \\ Marcos Felipe Silva Lino (iD \\ Universidade de Pernambuco, Brasil \\ http://lattes.cnpq.br/6258523475759480 \\ http://orcid.org/0000-0001-9059-7899 \\ marcoshit9@hotmail.com
}

Referencing this:

SILVA, C. M.; SILVA, V. R. M.; COSTA JÚNIOR, C. E. O.; SILVA FILHO, C. A.; LINO, M. F. S.. Chumbo e cádmio em água de poços artesianos da cidade de Buenos Aires-PE. Revista Ibero Americana de Ciências Ambientais, v.12, n.7, p.291-300, 2021. DOI:

http://doi.org/10.6008/CBPC2179-6858.2021.007.0027 


\section{INTRODUÇÃO}

A contaminação por metais pesados no meio ambiente é um grande problema de saúde pública no mundo. As atividades antropogênicas são as principais responsáveis pela presença desses elementos no meio ambiente, muitas vezes decorrentes da grande quantidade de resíduos sólidos gerados. No mundo globalizado são produzidas diariamente toneladas de resíduos sólidos. A disposição inadequada desses materiais preocupa, em decorrência do elevado potencial poluidor, como também pela falta de locais adequados para o descarte desses resíduos (KUCHARSKI et al., 2011).

Os metais pesados são compostos tóxicos e bioaculativos, sendo facilmente transferido para a cadeia alimentar através de diferentes vias de acessos. Uma vez presente na cadeia alimentar, e dependendo do valor das suas concentrações, os metais pesados podem causar danos aos sistemas biológicos, como toxicidades em plantas, animais e no homem (KUCHARSKI et al., 2011).

Os metais pesados são elementos naturais que possuem um alto peso atômico e uma densidade pelo menos 5 vezes maior do que a da água. Suas múltiplas aplicações industriais, domésticas, agrícolas, médicas e tecnológicas levaram a sua ampla distribuição no meio ambiente, trazendo muitas preocupações sobre seus efeitos potenciais na saúde humana e no meio ambiente. Sua toxicidade depende de vários fatores, incluindo a dose, a via de exposição e a espécie química, bem como a idade, sexo, genética e estado nutricional dos indivíduos expostos. Devido ao seu alto grau de toxicidade, arsênio, cádmio, cromo, chumbo e mercúrio estão entre os metais prioritários com significância para a saúde pública. Esses elementos metálicos são considerados tóxicos sistêmicos que induzem danos a múltiplos órgãos, mesmo em níveis mais baixos de exposição. Eles também são classificados como elementos carcinogênicos para os seres humanos, de acordo com a Agência de Proteção Ambiental dos Estados Unidos e a Agência Internacional de Pesquisa sobre o Câncer (TCHOUNWOU et al., 2012).

A água é uma substancia essencial para a vida, participando de vários processos biológicos, além de ser um solvente universal. Em decorrência da sua relevância para a qualidade de vida dos seres humanos, o monitoramento das fontes de água é um procedimento técnico necessário para constatar os níveis de concentração de metais pesados. Sendo assim, a monitoração dos recursos hídricos é de fundamental importância para se ter água de boa qualidade para suprir as necessidades dos seres humanos. Com isso, é possível obter níveis de potabilidades dentro da faixa de segurança aceitável para o consumo humano, de acordo com a legislação vigente (FERRAZ et al., 2018).

O município de Buenos Aires encontra-se localizado na Zona da Mata Norte do Estado de Pernambuco, com população de aproximadamente, 14.000 mil habitantes, tendo sua área territorial dividida em zona rural e meio urbano. O sistema de abastecimento público de água no município é realizado pela Companhia Pernambucana de Saneamento (COMPESA). Por outro lado, em decorrência da constante falta de água, a população local utiliza a água de poços amazonas do tipo cacimbão para satisfazer às suas necessidades de consumo, principalmente durante o verão, quando existe grande escassez de recursos hídricos. 
Em toda a região da Mata Norte, a agricultura canavieira é a principal atividade econômica. O município de Buenos Aires tem como base de sua economia o cultivo da cana-de-açúcar. A irrigação da canade-açúcar é realizada por água de reuso. O solo utilizado no cultivo da cana-de-açúcar na região da Mata Norte de Pernambuco é adubado com fertilizantes fosfatados. No Brasil, os fertilizantes fosfatados são obtidos através do beneficiamento das rochas fosfáticas. 0 grande problema é que esse tipo de rocha possui níveis elevados de metais pesados (CAMARGO et al., 2000). Água de reuso utilizada para irrigação, dependendo da sua origem, pode conter quantidades significativas de metais pesados (RAMALHO et al., 1999).

Uma vez no solo, os metais pesados são percolados para o lençol freático, entrando assim, na cadeia alimentar. Outro fato importante que deve ser levado em consideração no município de Buenos Aires, é a utilização indiscriminada de fertilizantes fosfatados nas lavouras de subsistência. Além disso, alguns poços utilizados como fonte de abastecimento de água para a população encontram-se localizados próximos do aterro sanitário do município ("Lixão municipal”). O chorume gerado em aterros sanitários possui concentrações significativas de metais pesados. Em decorrência da percolação, o chorume pode atingir os cursos d'água subterrâneos, causando risco à saúde da população (CELERE et al., 2007).

Sendo assim, e dentro desse contexto, o objetivo do presente trabalho foi determinar as concentrações de cádmio e chumbo em água de poços artesianos do tipo cacimbão, utilizados como fonte de abastecimento pela população do município de Buenos Aires - PE.

\section{METODOLOGIA}

\section{Local da pesquisa}

A pesquisa foi realizada no município de Buenos Aires localizado na Zona da Mata Norte do Estado de Pernambuco (Figura 1). O município de Buenos Aires - PE tem aproximadamente, 14.000 mil habitantes, segundo o último censo do Instituto Brasileiro de Geografia e Estatística-IBGE. Segundo o Ministério de Minas Energia (BRASIL, 2005), o referido município encontra-se localizado acima do domínio hidrogeológico no meio fissural das formações de rochas cristalinas, possuindo 15 pontos de água subterrâneas distribuídos entre propriedades privadas e públicas.

\section{Critérios de seleção das amostras}

O município de Buenos Aires - PE possui abundante fonte de lenções freáticos que são explorados pela população na forma de poços artesianos do tipo cacimbão. Entretanto, a água é consumida in natura sem tratamento prévio. Cinco (5) desses poços são muito utilizados pela população local, sendo dois (2) deles localizados próximos ao aterro sanitário do referido município ("Lixão" do município). Apesar de serem bastante utilizados como fonte alternativa de abastecimento público, não existe um estudo de monitoramento de metais pesados na água dos poços. Os cinco poços citados são os mais utilizados pelos habitantes para satisfazer às suas necessidades de consumo de água. Sendo assim, esses poços foram os 
objetos de estudos da presente pesquisa.

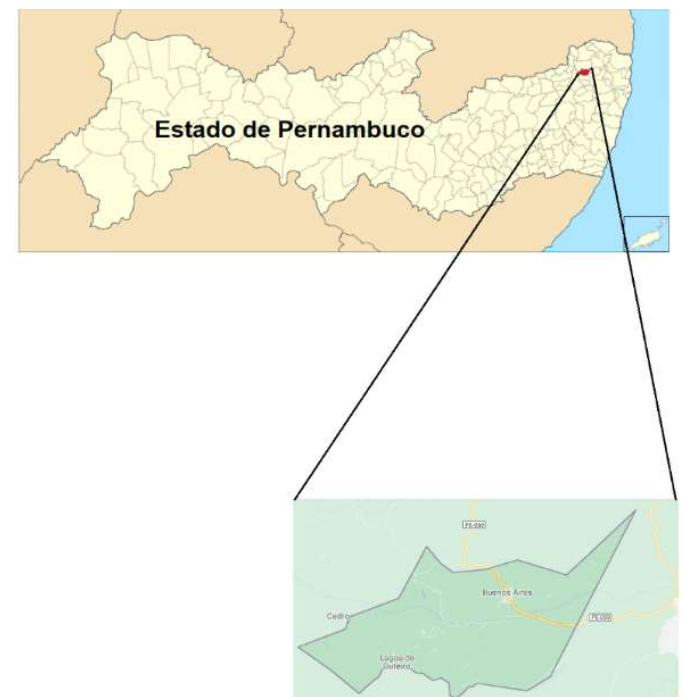

Figura 1: Localização do município de Buenos Aires no mapa de Pernambuco.

\section{Procedimentos de coleta e preparação das amostras}

Incialmente, as amostras foram coletadas durante o mês de dezembro do ano de 2020, seguindo todos os procedimentos técnicos estabelecidos pela American Public Health Association (APHA et al., 1998). A Figura 2 mostra os locais aonde foram realizadas as coletas.

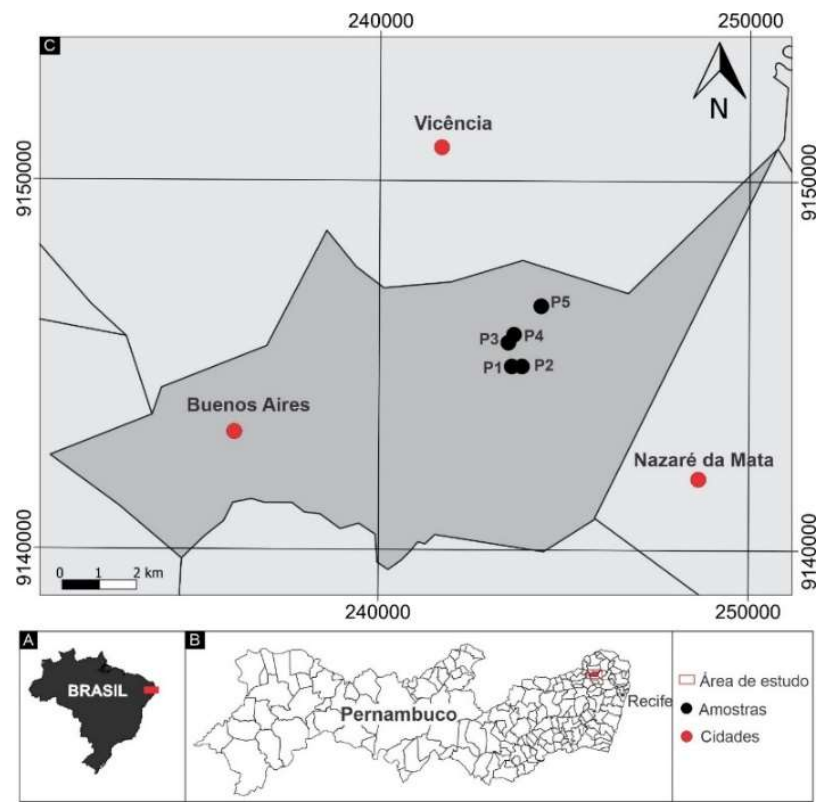

Figura 2: Locais de amostragem.

Os poços foram numerados de 1 a 5 para facilitar a sua localização no mapa do município de Buenos Aires - PE, como também fornecer detalhes de sua historicidade na comunidade, conforme descrito abaixo.

Poço 1 (Figura 3). Chamado popularmente como Cacimba de Maduro. Encontra-se localizado próximo ao aterro sanitário do município, na comunidade da Rua da Palha, cujos habitantes utilizam da sua água para o consumo e limpeza domiciliar.

Poço 2 (Figura 4). Conhecido como Forminha, esse poço localiza-se próximo a um pasto bovino e residências. Ele é bastante utilizado pelos moradores para comércio da água e consumo. 
Poço 3 (Figura 5). Esse poço é conhecido como Cacimba de Maria de Cotinha, e encontra-se localizado na zona Urbana, na Rua Projetada 21. Esse é um dos poços mais utilizado pela comunidade local, cuja água é bastante consumida em diferentes afazeres domésticos.

Poço 4 (Figura 4). Na região, esse poço é conhecido como Cacimba de Machado, e está localizado próximo às lavouras de cultivos de hortaliças, tendo ao lado esgoto a céu aberto. Além de ser utilizada no cultivo de hortaliças, a água desse poço é muito usada para abastecimento público dos residentes.

Poço 5 (Figura 7). Esse poço é conhecido como Cacimba de João Avelino, estando situado na Zona Rural, sendo o poço mais distante do centro do município. Esse poço é o mais usado pela população em geral.

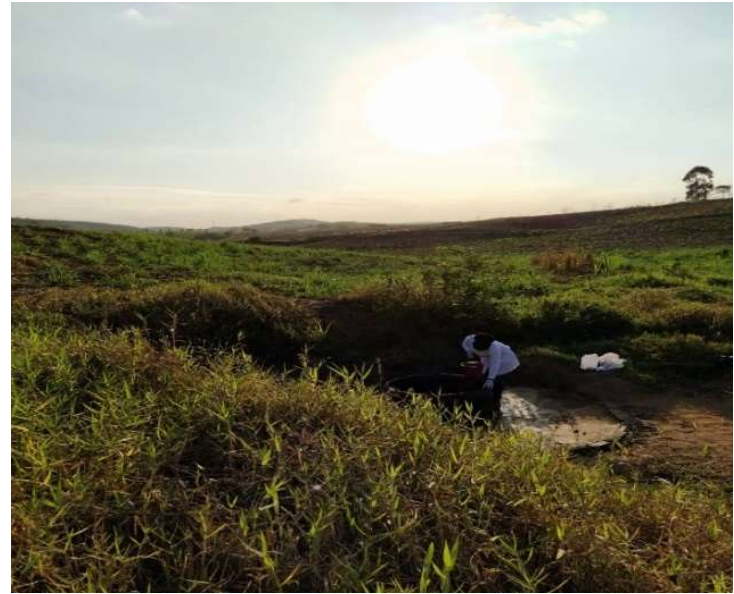

Figura 3: Localização do Poço 1.

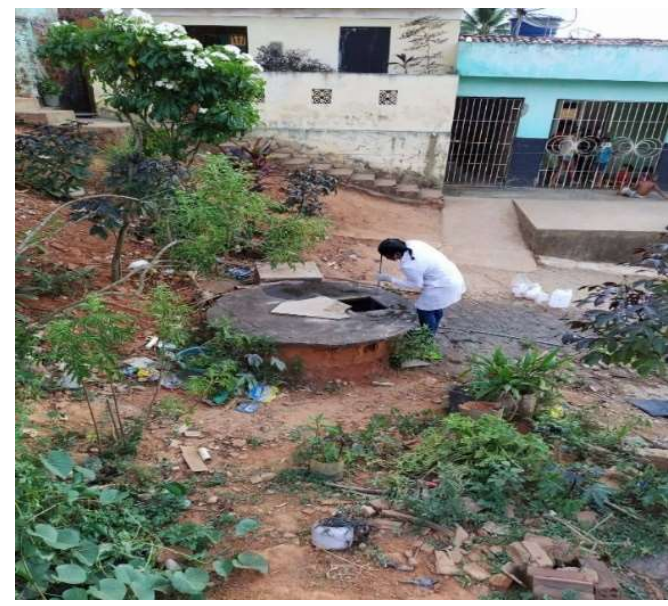

Figura 5: Localização do Poço 3.

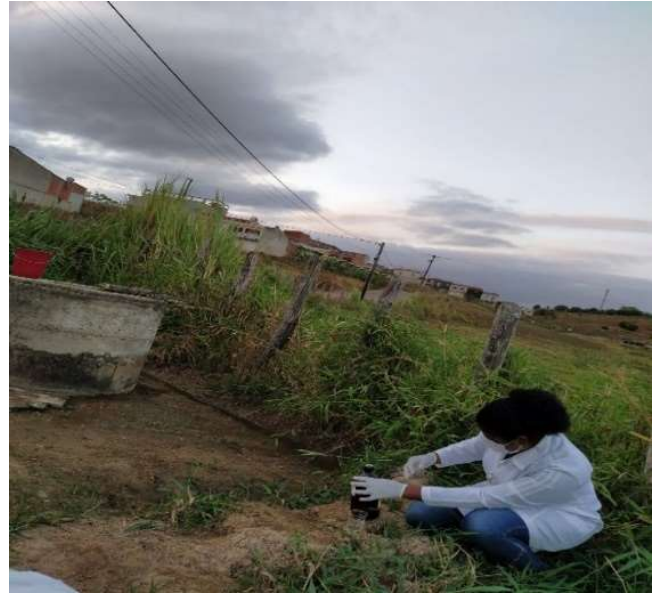

Figura 4: Localização do Poço 2.

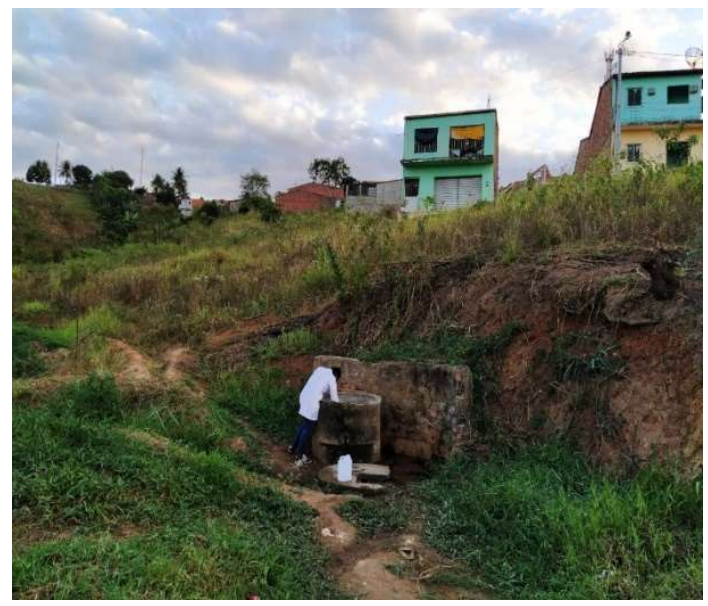

Figura 6: Localização do Poço 4.

Em cada local de amostragem foram coletados cinco (5) litros de água em recipientes de polietileno, e em seguida foram adicionados ácido nítrico concentrado (pronto para análise), até obter pH igual ou menor do que 2 (APHA et al., 1998). Tal procedimento foi utilizado para evitar que os metais pesados adsorvessem nas paredes do recipiente. Em cada poço, as amostras de água foram coletadas e acidificadas com ácido nítrico concentrado, e depois os recipientes de polietileno foram vedados antes de serem levados ao laboratório. As Figuras 8, 9 e 10 mostram os procedimentos de coleta e acidificação das amostras de água in loco, como também a vedação do recipiente de acondicionamento. 


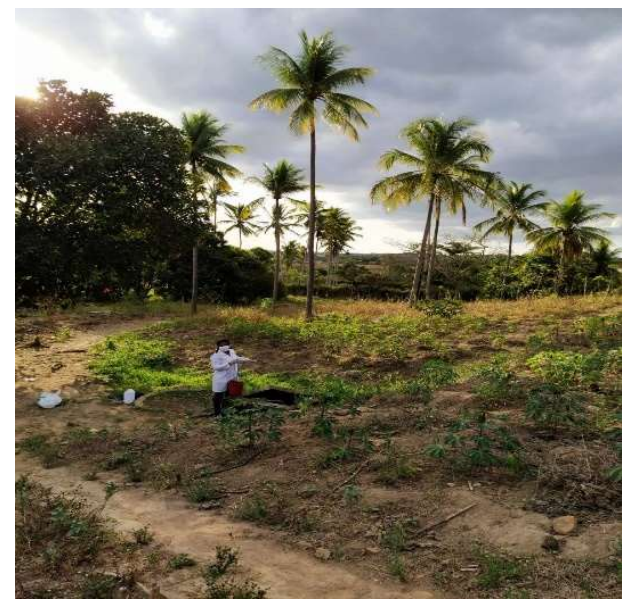

Figura 7: Localização do Poço 5.

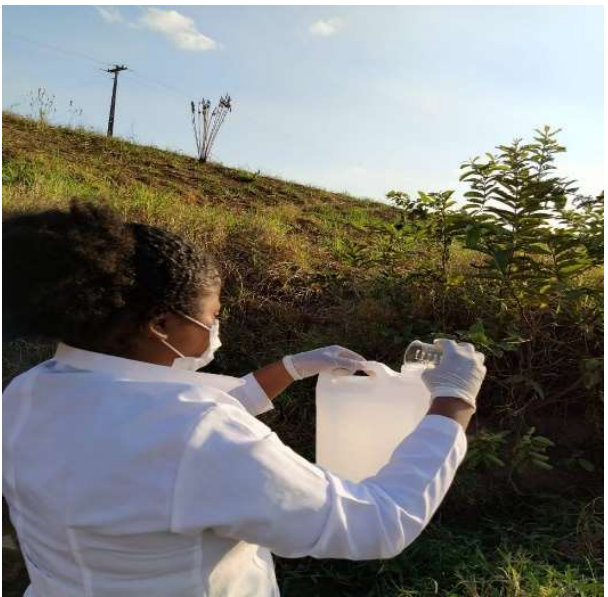

Figura 9: Acidificação da água coletada no Poço 1.

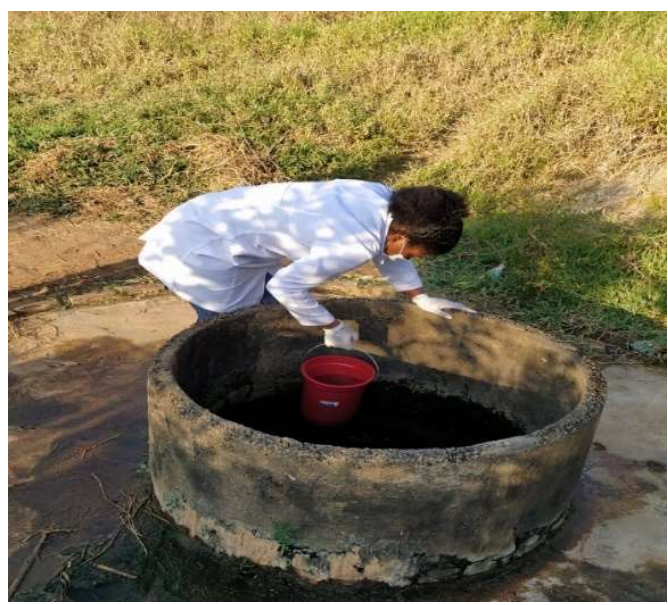

Figura 8: Coleta de água no Poço 1.

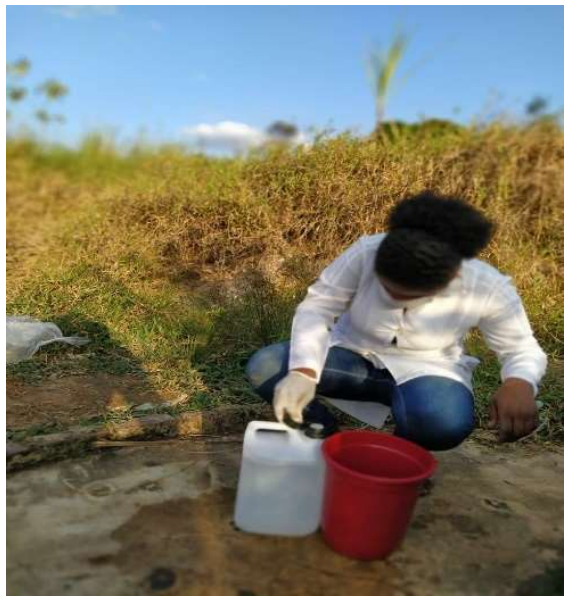

Figura 10: Vedação do recipiente contendo água coletada no Poço 1.

Depois dos procedimentos de coleta, as amostras foram acondicionadas e levadas ao laboratório. No laboratório, as amostras foram filtradas e agitadas, e em seguida foram retirados $50 \mathrm{ml}$ de cada para a determinação do cádmio $(\mathrm{Cd})$ e do chumbo $(\mathrm{Pb})$. Nesse caso, o cádmio e o chumbo foram determinados pela técnica de espectrometria de massa num equipamento ICP-MS da marca PerkinElmer modelo NexION 300D (Figura 11). Todas as análises foram realizadas no Laboratório de Monitoração Ambiental do Centro Regional de Ciências Nucleares (CRCN) da Comissão Nacional de Energia Nuclear (CNEN), na cidade do Recife.

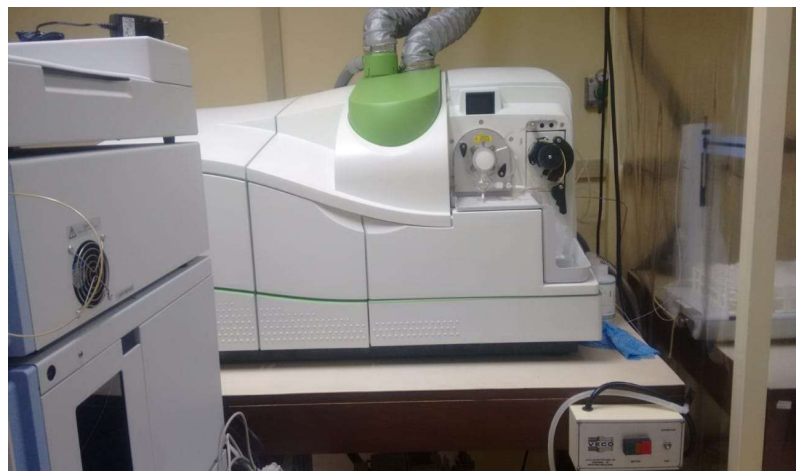

Figura 11: Equipamento de ICP-MS

\section{RESULTADOS E DISCUSSÃO}

Como pode ser observado na Tabela 1, os valores das concentrações de chumbo $(\mathrm{Pb})$ e cádmio ( $\mathrm{Cd}$ ) 
nas amostras de água dos poços de 1 a 5 foram menores do que o limite de detecção (LD).

Tabela 1. Concentração de $\mathrm{Pb}$ e Cd nas amostras de água dos Poços 1 a 5, LD e LQ.

\begin{tabular}{|c|c|c|}
\hline \multirow[t]{2}{*}{ Amostra } & \multicolumn{2}{|c|}{ Concentração ( $\left.\mu \mathrm{g} \cdot \mathrm{L}^{-1}\right)$} \\
\hline & $\mathrm{Pb}$ & $\mathrm{Cd}$ \\
\hline Poço 1 & $<\mathrm{LD}$ & $<\mathrm{LD}$ \\
\hline Poço 2 & $<\mathrm{LD}$ & $<\mathrm{LD}$ \\
\hline Poço 3 & $<\mathrm{LD}$ & $<\mathrm{LD}$ \\
\hline Poço 4 & $<\mathrm{LD}$ & $<\mathrm{LD}$ \\
\hline Poço 5 & $<\mathrm{LD}$ & $<\mathrm{LD}$ \\
\hline LD* & 0,6 & 0,1 \\
\hline $\mathrm{LQ}^{*}$ & 0,8 & 0,2 \\
\hline
\end{tabular}

*LD = Limite de detecção e LQ = limite de quantificação.

De acordo com o que se encontra estabelecido nos Artigos 49 e 50 sobre limite de detecção (LD) existente na Resolução RDC no 166, de 24 de julho de 2017, da Agência Nacional de Vigilância Sanitária (ANVISA) do Ministério da Saúde do Brasil (BRASIL, 2017), pode-se afirmar:

Limite de detecção deve ser demonstrado pela obtenção da menor quantidade do analito presente em uma amostra que pode ser detectado, porém, não necessariamente quantificado, sob as condições experimentais estabelecidas. A determinação do limite de detecção pode ser realizada por meio de método visual, da razão sinal-ruído, baseado na determinação do branco ou em parâmetros da curva de calibração, considerando-se as particularidades do método analítico utilizado.

A Resolução RDC no 166 (BRASIL, 2017) nos artigos 55 e 56 define também o limite de quantificação (LQ):

O limite de quantificação é a menor quantidade do analito em uma amostra que pode ser determinada com precisão e exatidão aceitáveis sob as condições experimentais estabelecidas. O limite de quantificação deve ser coerente com o limite de especificação da impureza.

Estudos realizados por Silva et al. (2019) mostraram a importância da determinação do limite de detecção (LD) em procedimentos analíticos de análises químicas quantitativas. De acordo com esses autores, é possível criar intervalo de confiança robusto para o LD, usando o método estatístico bootstrap. Certamente, isso é de crucial importância para se conhecer os níveis de concentração de um determinado contaminante numa amostra qualquer. No caso específico dos valores apresentados na Tabela 1, as concentrações de chumbo e cádmio foram tão baixas que ficaram dentro do intervalo de contagem das amostras do "branco" (background), não sendo possível quantifica-las. Isso não significa necessariamente, que não existe chumbo e cádmio nas águas dos poços 1 a 5 (Tabela 1), mas, que seus níveis de concentração são tão baixos, que se pode considera-los analiticamente desprezíveis. Isso é muito importante do ponto de vista da saúde pública.

A Organização Mundial de Saúde (OMS) estabeleceu o limite de $10,0 \mu \mathrm{g} \cdot \mathrm{L}^{-1}$ e 3,0 $\mu \mathrm{g} \cdot \mathrm{L}^{-1}$, respectivamente, para o chumbo e cádmio em água para consumo humano (WHO, 2011). Por outro lado, a legislação brasileira editada pelo Conselho Nacional do Meio Ambiente (CONAMA, 2005) estabeleceu os

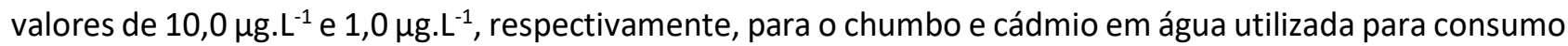
humano. Assim, os valores das concentrações de chumbo e cádmio dos poços 1 a 5 (Tabela 1) foram significativamente menores do que estabelece a lei brasileira (CONAMA, 2005) e a OMS (WHO, 2011).

Os valores das concentrações de chumbo e cádmio apresentados na Tabela 1 foram provenientes de água coletada durante o verão (mês de dezembro/2020), quando os lençóis freáticos, geralmente, 
encontram-se no seu menor nível aquático. Nesse caso, as concentrações de qualquer contaminante deveriam ser maiores, em decorrência da menor diluição em solução. Sendo assim, mesmo tendo sido coletadas num período de menor diluição, as amostras de água dos poços 1 a 5 (Tabela 1) apresentaram valores de concentrações insignificantes do ponto de vista da saúde pública. Isso significa que, do ponto de vista sanitário, os valores apresentados na Tabela 1 são insuficientes para induzir níveis de toxicidade química capazes de causar danos à saúde dos moradores do município de Buenos Aires.

Os níveis de concentrações desprezíveis de cádmio e chumbo nas águas dos poços 1 a 5 (Tabela 1), significa que, apesar da localidade onde eles foram construídos apresentarem agentes potencialmente poluidores de metais pesados, tais com a adubação do solo com fertilizantes fosfatado na monocultura canavieira e água de irrigação poluída (RAMALHO et al., 1999) e aterro sanitário (CELERE et al., 2007), como no caso do poço 1 , não existe migração quimicamente significativa desses elementos contaminantes para os lençóis freáticos.

A literatura especializada apresenta diversos estudos no Brasil e no mundo sobre níveis elevados de concentração de chumbo e cádmio em águas de poços artesianos, com valores acima dos limites máximos estabelecidos pela Organização Mundial de Saúde (WHO, 2011). Apesar das concentrações de chumbo e cádmio apresentarem valores abaixo do limite de detecção (LD) (Tabela 1), por questão de comparação, foram citados trabalhos realizados no Brasil e no mundo, com a finalidade de mostrar o potencial poluidor desses elementos químicos em poços artesianos, como segue abaixo.

Trabalhos de pesquisa realizados por Ferraz et al. (2018) em diferentes poços artesianos localizados na cidade de Vitória da Conquista, no sudoeste do Estado da Bahia, apresentaram concentrações médias de chumbo e cádmio variando de 154,0 a $173,0 \mu \mathrm{g} \cdot \mathrm{L}^{-1}$ e de 3.0 a $3.4 \mu \mathrm{g} \cdot \mathrm{L}^{-1}$, respectivamente.

A água subterrânea é uma das fontes importantes de água potável na cidade de Jijel, no Nordeste da Argélia. Nessa localidade, análises químicas mostraram concentrações críticas de chumbo e cádmio em diferentes fontes de água subterrânea usadas para o abastecimento público. Estudos realizados por Balli et al. (2018), em oito poços artesianos perfurados na cidade de Jijel, apresentaram concentrações elevadas de chumbo e cádmio, variando de 72,84 a $458,95 \mu \mathrm{g} \cdot \mathrm{L}^{-1}$ e de 12,41 a $33,0 \mu \mathrm{g} \cdot \mathrm{L}^{-1}$, respectivamente.

Quando comparadas com os valores apresentados na literatura especializada, verifica-se o quanto as concentrações de chumbo e cádmio nas águas dos poços 1 a 5 (Tabela 1) foram significativamente desprezíveis como agentes causadores de toxicidade química em seres humanos. Portanto, em relação à potabilidade da presença de metais pesados, a água dos poços 1 a 5 (Tabela 1) apresenta concentrações de chumbo e cádmio muito abaixo dos limites máximos permitidos pela lei brasileira (CONAMA, 2005) e a OMS (WHO, 2011). Isso significa que, do ponto de vista da presença de chumbo e cádmio, a ingestão de água dos poços 1 a 5 pela população local, não acarreta danos à saúde.

O monitoramento ambiental desempenha um papel fundamental para garantir a qualidade da água utilizada para o consumo humano. A contaminação da água com metais pesados é um dos fatores de risco elevado à saúde humana. Sendo assim, cabe aos órgãos responsáveis pela saúde pública, especificamente, a Vigilância Sanitária, criar programas de monitoração dos recursos hídricos utilizados como fonte de 
abastecimento público. As leis brasileiras devem ser rígidas e exigir medidas preventivas para manter a potabilidade da água usada para consumo humano, em relação à presença de metais pesados.

Para desenvolver um programa de monitoração ambiental abrangente, em relação à presença de metais pesados nos recursos hídricos, as instituições responsáveis precisam determinar as áreas onde possam existir riscos em potenciais, estabelecer controles preventivos e verificar se esses controles são eficazes. Assim, as equipes técnicas das instituições são fortemente recomendadas a coletar periodicamente, dentro de um plano de metas estrategicamente definido, amostras de água de diferentes localidades, especialmente em áreas com riscos potenciais. Se as instituições de vigilância à saúde pública estadual ou municipal não aderirem a um cronograma de monitoração ambiental de metais pesados com amostragem periódica dos recursos hídricos de abastecimento público, corre o risco de comprometer a saúde dos seus cidadãos.

Apesar dos estudos preliminares realizados na água dos poços 1 a 5 apresentarem concentrações de chumbo e cádmio desprezíveis (Tabela 1), nada garante que, futuramente surjam pontos de contaminação elevados no aquífero onde os poços encontram-se localizados. Daí a importância de se estabelecer um programa de monitoração ambiental para avaliar periodicamente a água dos poços 1 a 5 (Tabela 1) e garantir a sua potabilidade. Tal programa pode ser desenvolvido em parceria técnica entre a Vigilância Sanitária da Prefeitura Municipal de Buenos Aires, Secretaria Estadual de Saúde de Pernambuco (SES-PE) e a Companhia Pernambucana de Saneamento (COMPESA).

A cidadania do acesso à água é um direito de cada indivíduo dentro de um estado democraticamente estabelecido, e deve o poder público garanti-lo. Dentro dos 17 Objetivos de Desenvolvimento Sustentável estabelecidos pela Organização das Nações Unidas (ONU), na Agenda 2030, o Objetivo 6 faz referência ao acesso democrático à água, ao mencionar o direito de assegurar a disponibilidade e a gestão sustentável desse importante recurso. Então, gerir os recursos hídricos onde estão localizados os poços 1 a 5 (Tabela 1), é responsabilidade ambiental de cada cidadão e dos órgãos públicos, tendo como finalidade principal o acesso democrático ao uso da água pelos habitantes do município de Buenos Aires.

\section{CONCLUSÕES}

Em relação aos poços artesianos do tipo cacimbão estudados no município de Buenos Aires-PE, os níveis de concentração de chumbo e cádmio na água foram significativamente menores do que os valores máximos permitidos pela Organização Mundial de Saúde (OMS) e pelo Conselho Nacional do Meio Ambiente (CONAMA) do Brasil. Até a presente data, os níveis de concentração de chumbo e cádmio na água dos poços estudados oferecem riscos desprezíveis de toxidade química para os seres humanos.

Apesar dos estudos preliminares terem mostrado níveis desprezíveis de concentração de chumbo e cádmio na água dos poços estudados, existe a necessidade de se estabelecer programas de monitoração ambiental periódica desses importantes recursos hídricos, com a finalidade de se observar possíveis alterações da presença desses metais pesados no aquífero da região. 


\section{REFERÊNCIAS}

APHA; AWWA; WEF. American Public Health Association; American Water Works Association; Water Environment Federation. Standard methods for the examination of water and wastewater. 20 ed. Washington: APHA, 1998.

BALLI, N.; LEGHOUCHI, E.. Assessment of lead and cadmium in groundwater sources used for drinking purposes in Jijel (Northeastern Algeria). Global NEST Journal, v.20, n.2, p.417-423, 2018.

BRASIL. Ministério da Saúde do Brasil. Agência Nacional de Vigilância Sanitária. Resolução da Diretoria Colegiada - RDC no 166, de 24 de julho de 2017 (Publicada no DOU no 141, de 25 de julho de 2017). Dispõe sobre a validação de métodos analíticos e dá outras providências. ANVISA, 2017.

BRASIL. Ministério das Minas e Energia do Brasil. Projeto cadastro de fontes de abastecimento por água subterrânea (Pernambuco). Diagnóstico do município de Buenos Aires. Serviço Geológico do Brasil- CPRM, 2005.

CAMARGO, M. S.; ANJOS, A. R. M.; ROSSI, C.; MALAVOLTA, E.. Adubação fosfatada e metais pesados em latossolo cultivado com arroz. Scientia Agricola, v.57, n.3, p.513-518, 2000. DOI: http://doi.org/10.1590/S0103$\underline{90162000000300022}$

CELERE, M. S.; OLIVEIRA, A. S.; TREVILATO, T. M. B.; MUÑOZ, S. I. S.. Metais pesados no chorume coletado no aterro sanitário de Ribeirão Preto, São Paulo, Brasil, e sua relevância para saúde pública. Cadernos de Saúde Pública, v.23, n.4, p.939-947, 2007. DOI:

http://doi.org/10.1590/S0102-311X2007000400021

CONAMA. Conselho Nacional do Meio Ambiente. Resolução CONAMA no 357, de 17 de março de 2005. Dispõe sobre a classificação dos corpos de água e diretrizes ambientais para o seu enquadramento, bem como estabelece as condições e padrões de lançamento de efluentes, e dá outras providências. CONAMA, 2005.

FERRAZ, L. L.; DOURADO, A. A.; RODRIGUES, A.; ROCHA, F. A.. Análise da presença de metais pesados na água em diferentes reservatórios subterrâneos no município de Vitória da Conquista-BA. Agrarian Academy, Centro Científico Conhecer, Goiânia, v.5, n.9, p.1-9, 2018. DOI: http://doi.org/10.18677/Agrarian Academy 2018a1

KUCHARSKI, S. C. R. P.; BARBOSA, R. M.; NUNES, F. C.; BRITO, F. J. O.; SILVA, E. F.. Avaliação de metais pesados em solos e sedimentos do grupo barreiras sob deposito de resíduos sólidos urbanos-casos de Cana Brava-Salvador-Bahia. Rio de Janeiro: EMBRAPA solos, 2011.

RAMALHO, J. F. G. P.; SOBRINHO, N. M. B. A; VELLOSO, A. C. $X$. .. Acúmulo de metais pesados em solos cultivados com cana-de-açúcar pelo uso contínuo de adubação fosfatada e água de irrigação. Revista Brasileira de Ciência do Solo, v.23, p.971-979, 1999. DOI: http://doi.org/10.1590/s0100$\underline{06831999000400024}$

SILVA, C. M.; VIEIRA, J. W.; COSTA JÚNIOR, C. E. O.. Bootlimit: uma aplicação em radioquímica. Nucleus, v.16, n.2, 2019. DOI: http://doi.org/10.3738/1982.2278.3604

TCHOUNWOU, P. B.; YEDJOU, C. G.; PATLOLLA, A. K.; DWAYNE J. SUTTON, D. J.. Heavy metal toxicity and the environment. Molecular, Clinical and Environmental Toxicology, v.101, p.133-164, 2012.

DOI: http://doi.org/10.1007/978-3-7643-8340-4 6

WHO. World Health Organization. Guidelines for drinkingwater quality. WHO, 2011.

A CBPC - Companhia Brasileira de Produção Científica (CNPJ: 11.221.422/0001-03) detém os direitos materiais desta publicação. Os direitos referem-se à publicação do trabalho em qualquer parte do mundo, incluindo os direitos às renovações, expansões e disseminações da contribuição, bem como outros direitos subsidiários. Todos os trabalhos publicados eletronicamente poderão posteriormente ser publicados em coletâneas impressas sob coordenação da Sustenere Publishing, da Companhia Brasileira de Produção Científica e seus parceiros autorizados. Os (as) autores (as) preservam os direitos autorais, mas não têm permissão para a publicação da contribuição em outro meio, impresso ou digital, em português ou em tradução. 